\title{
Mortality attributable to influenza-like illness, gastro- enteritis and pneumonia, results from the Dutch Sentinel Network for Surveillance of Infectious Disease (SNIV)
}

\author{
M-J Veldman-Ariesen, L van Asten, AP Haenen, M Kretzschmar, BH van Benthem*, SNIV study group \\ From International Conference on Prevention \& Infection Control (ICPIC 2011) \\ Geneva, Switzerland. 29 June - 2 July 2011
}

\section{Introduction / objectives}

Elderly and especially nursing home residents are at increased risk of infectious diseases due the high prevalence of underlying chronic illnesses, age-related immunesenesence and the close(d) environment typical for this population. The impact of the occurence of infectious diseases on mortality is subject of this study.

\section{Methods}

In the Sentinel Surveillance Network on Infectious diseases in nursing homes (SNIV), elderly care physicians and/or nurse practitioners report weekly numbers of 1) mortality and 2) infectious diseases on the basis of clinical definition. On these weekly time series (mid 2008- beginning of 2011) we used Poisson regression models (which included linear and periodic components) to characterize the association of total death counts with trends in influenza-like illness (ILI), gastro-enteritis (GE), and probable pneumonia.

\section{Results}

In total 35 nursing homes with a total of 4516 residents participated during part of the 128 week study period. The incidence of mortality and infectious illnesses displayed seasonal peaks in winter. In total 2324 residents died. Â Per 1000 residents, each reported case of pneumonia was associated with 3.4 (95\%CI:1.7-5.2) deaths occurring in the same week and 2.2 (95\% CI:0.5-3.9) occurring 2 weeks later. Each reported GE case was associated with 1.1 (95\%CI:0.4-1.7) deaths one week later. Together with these

Epidemiology and Surveillance Unit, Dutch National Institute for Public Health and the Environment (RIVM), Centre for Infectious Disease Control, Bilthoven, Netherlands infections, the linear and periodic terms were no longer significant and were thus excluded from the final model. Of all deaths, our model attributed 745 (32\%) to pneumonia and $172(7 \%)$ to GE.

\section{Conclusion}

Probable pneumonia and gastro-enteritis were significantly associated with overall mortality, while influenza-like illness was not.

\section{Disclosure of interest}

None declared.

Published: 29 June 2011

\section{doi:10.1186/1753-6561-5-S6-P166}

Cite this article as: Veldman-Ariesen et al:: Mortality attributable to influenza-like illness, gastro-enteritis and pneumonia, results from the Dutch Sentinel Network for Surveillance of Infectious Disease (SNIV). BMC

Proceedings 2011 5(Suppl 6):P166.

Submit your next manuscript to BioMed Central and take full advantage of:

- Convenient online submission

- Thorough peer review

- No space constraints or color figure charges

- Immediate publication on acceptance

- Inclusion in PubMed, CAS, Scopus and Google Scholar

- Research which is freely available for redistribution

Submit your manuscript at www.biomedcentral.com/submit 